\title{
Interdecadal changes on the seasonal prediction of the western North Pacific summer climate around the late 1970s and early 1990s
}

Article

Accepted Version

Li, C., Lu, R. and Dong, B. (2016) Interdecadal changes on the seasonal prediction of the western North Pacific summer climate around the late 1970s and early 1990s. Climate Dynamics, 46 (7-8). pp. 2435-2448. ISSN 0930-7575 doi: https://doi.org/10.1007/s00382-015-2711-1 Available at https://centaur.reading.ac.uk/53078/

It is advisable to refer to the publisher's version if you intend to cite from the work. See Guidance on citing.

Published version at: http://link.springer.com/article/10.1007\%2Fs00382-015-2711-1

To link to this article DOI: http://dx.doi.org/10.1007/s00382-015-2711-1

Publisher: Springer

All outputs in CentAUR are protected by Intellectual Property Rights law, including copyright law. Copyright and IPR is retained by the creators or other copyright holders. Terms and conditions for use of this material are defined in the End User Agreement. 


\section{CentAUR}

Central Archive at the University of Reading

Reading's research outputs online 
Interdecadal changes on the seasonal prediction of the western North Pacific

\section{summer climate around the late 1970s and early 1990s}

\author{
Chaofan $\mathrm{Li}^{1}$, Riyu $\mathrm{Lu}^{2}$ and Buwen Dong ${ }^{3}$
}

1 Center for Monsoon System Research, Institute of Atmospheric Physics, Chinese Academy of Sciences, Beijing 100029, China

2 State Key Laboratory of Numerical Modelling for Atmospheric Sciences and Geophysical Fluid Dynamics, Institute of Atmospheric Physics, Chinese Academy of Sciences, Beijing 100029, China

3 National Centre for Atmospheric Science-Climate, Department of Meteorology, University of Reading, Reading, United Kingdom

Submitted to Climate Dynamics

Revised in April 2015

Revised in June 2015

Corresponding author:

Chaofan $\mathrm{Li}$

Institute of Atmospheric Physics,

Chinese Academy of Sciences,

P.O. Box 9804, Beijing 100029, China

Email: lichaofan@mail.iap.ac.cn

Tel: +86-10-8299-5280 
Identifying predictability and the corresponding sources for the western North Pacific (WNP) summer climate in the case of non-stationary teleconnections during recent decades benefits for further improvements of long-range prediction on the WNP and East Asian summers. In the past few decades, pronounced increases on the summer sea surface temperature (SST) and associated interannual variability are observed over the tropical Indian Ocean and eastern Pacific around the late 1970s and over the Maritime Continent and western-central Pacific around the early 1990s. These increases are associated with significant enhancements of the interannual variability for the lower-tropospheric wind over the WNP. In this study, we further assess interdecadal changes on the seasonal prediction of the WNP summer anomalies, using May-start retrospective forecasts from the ENSEMBLES multi-model project in the period 1960 to 2005. It is found that prediction of the WNP summer anomalies exhibits an interdecadal shift with higher prediction skills since the late 1970s, particularly after the early 1990s. Improvements of the prediction skills for SSTs after the late 1970s are mainly found around tropical Indian Ocean and the WNP. The better prediction of the WNP after the late 1970s may arise mainly from the improvement of the SST prediction around the tropical eastern Indian Ocean. The close teleconnections between the tropical eastern Indian Ocean and WNP summer variability work both in the model predictions and observations. After the early 1990s, on the other hand, the improvements are detected mainly around the South China Sea and Philippines for the lower-tropospheric zonal wind and precipitation anomalies, 

associating with a better description of the SST anomalies around the Maritime Continent. A dipole SST pattern over the Maritime Continent and the central equatorial Pacific Ocean is closely related to the WNP summer anomalies after the early 1990s. This teleconnection mode is quite predictable, which is realistically reproduced by the models, presenting more predictable signals to the WNP summer climate after the early 1990s.

56

Key words: Western North Pacific, Seasonal forecast, Interdecadal change, Air-sea interaction, ENSEMBLES 


\section{Introduction}

Large year-to-year variability of the summer climate is displayed over the western North Pacific (WNP) and East Asia, resulting in disastrous floods and droughts over East Asia. This variability will be enhanced under the background of global warming ( $\mathrm{Lu}$ and $\mathrm{Fu}$ 2009). Interannual variation of the WNP summer climate, which has pronounced impacts on the climate over East Asia (e.g., Huang and Sun 1992; Wang et al. 2000; Lu and Dong 2001), acts as a basis for identifying the variation and long-range prediction of East Asian summer climate. Thus, understanding the predictability of the WNP summer climate under different backgrounds of the changing climate is of particular importance.

Current coupled models exhibit a somewhat reliable capability in predicting seasonal anomalies of precipitation and circulation over the WNP (Lee et al. 2011; Li et al. 2012; Kosaka et al. 2013). This reliability arises mainly from its teleconnections with El Niño-Southern Oscillation (ENSO) forcing and monsoon-ocean interactions in the tropical Indian Ocean (e.g., Chowdary et al. 2009; Wang et al. 2009). Using five state-of-the-art coupled models from ENSEMBLES forecast system, Li et al. (2012) presented a comprehensive assessment on the predictability of the WNP summer climate and suggested a skillful prediction on the atmospheric anomalies and a good representation on the associated atmosphere-ocean interactions over the tropical Indian and Pacific Ocean. In addition, good predictions of the WNP summer anomalies are found even during the years when there are no significant ENSO-related SST anomalies (Li et al. 2014). It suggests that the local 
atmosphere-ocean interactions act as another important role in the predictability of the WNP summer climate. Kosaka et al. (2013) proposed a coupled mode arising from interactions between the tropical Indian Ocean sea surface temperature (SST) and Pacific-Japan teleconnection pattern during boreal summer, as the origin of seasonal predictability for the WNP summer climate. They pointed out that this Pacific-Japan and Indian Ocean coupled mode is quite predictable and can exist without ENSO.

However, it should be noticed that interannual variation of the WNP summer climate and associated tropical SSTs displays remarkable interdecadal changes during the past few decades (e.g., Kwon et al. 2005; Wang et al. 2008; Park et al. 2010; Xie et al. 2010). Around the late 1970s, the WNP subtropical high shows an increase on its interannual variability with an enhanced relative vorticity at the middle and lower troposphere over the WNP and more water vapor transport from Indian summer monsoon (e.g., Huang et al. 2015). The SST in the tropical Indian Ocean and equatorial eastern Pacific has been noticed to have remarkable local or remote effects on these changes (Wang et al. 2008; Huang et al. 2010; Xie et al. 2010). Remarkable warming with an enhanced variability for these two major tropical SST variations is shown after the late 1970s, resulting in strengthened teleconnections with the WNP summer monsoon. It has been documented that fluctuations of the WNP summer climate can be affected by remote tropical SST anomalies. The tropical Indian Ocean SST anomalies, for instance, can excite a tropospheric Kelvin wave and induce robust atmospheric and precipitation anomalies over the WNP, particularly during the ENSO decaying summers (Terao and Kubota 2005; Yang et al. 2007; Li et al. 2008; Xie et al. 
2009).

Around the early 1990s, on the other hand, a clear interdecadal change on the WNP summer climate is also detected with a strengthened anomalous low-level anticyclone ( $\mathrm{Wu}$ et al. 2010). It is associated with an enhanced teleconnection between the WNP and East Asian summer monsoon after the early 1990s (Kwon et al. 2005; Park et al. 2010). This may result from enhanced fluctuations of precipitation and associated latent heat forcing over the WNP domain after the early 1990s, which is reflected by the interdecadal change of the dominant modes for the precipitation anomalies in the WNP and East Asian region (Kwon et al. 2005; Yim et al. 2008; Lee et al. 2014). It is different to that before the early 1990s, in which ENSO and related Indian Ocean warming dominate the interannual variation of the summer precipitation over the WNP and East Asian region (Wang et al. 2008). Lee et al. (2014) suggested that the WNP summer monsoon variability is significantly related to the SST anomalies over the central Pacific since the early 1990s rather than canonical ENSO-related forcing during 1979-1993. Some recent studies pointed out that the periodicity of the WNP subtropical high and the relative role of tropical SST forcing in the WNP subtropical high demonstrated significant decadal changes in the early 1990s and suggested that SST anomalies around the Maritime Continent and central Pacific contribute more to the WNP subtropical high after the early 1990s (e.g., Sui et al. 2007; He and Zhou 2015).

In view of the interdecadal changes of the WNP summer climate and associated tropical air-sea interactions in observations, whether the seasonal predictability for the 
WNP summer climate is changed on similar timescale? If so, what are the possible mechanisms for the changes of the prediction skills and sources of reliability? The above questions remain unclear and will be examined in the present study. To achieve this, the retrospective forecasts from ENSEMBLES multi-model project are used, which cover a long period from 1960 to 2005.

The remainder of this paper is organized as follows. Section 2 describes the models, datasets and methods used in this study. The interdecadal changes on the mean state and interannual variability are shown in Section 3. Section 4 presents the interdecadal changes in the prediction skill of the WNP summer climate, followed in Section 5 by an interpretation of possible reasons for the interdecadal changes in the predictability. And finally, the summary and discussion are given in Section 6 .

\section{Models, datasets and methods}

The models used in this study are five fully coupled atmosphere-ocean prediction systems from ENSEMBLES multi-model project, including the UK Met Office (UKMO), Météo-France (MF), the European Centre for Medium-Range Weather Forecasts (ECMWF), the Leibniz Institute of Marine Sciences at Kiel University (IFM-GEOMAR) and the Euro-Mediterranean Center for Climate Change (CMCC-INGV). All models include major radiative forcing and have no flux adjustments. The atmosphere and ocean were initialized using realistic estimation of their observed states. Each model was run from an ensemble of nine initial conditions. Further details on the ENSEMBLES multi-model project, the main model components and the initial condition perturbations are referred to Doblas-Reyes et al. 
(2010), Weisheimer et al. (2009) and van der Linden and Mitchell (2009).

The retrospective forecasts were carried out for a 46-year period of 1960-2005 on the above-described five models. For each year, the forecasts wereinitialized in 1st of May and performed seven-month long hindcasts. The multi-model-ensemble (MME) results were calculated through a simple composite by applying equal weight to all the five models.

The observed datasets for validating the model simulation include monthly mean National Centers for Environmental Prediction/National Center for Atmospheric Research (NCEP/NCAR) reanalysis data (Kalnay et al. 1996) and NOAA Extended Reconstructed monthly mean SST V3 dataset (Smith and Reynolds 2004), with the time period from 1960 to 2005 . The observational monthly precipitation data are obtained from Global Precipitation Climatology Project (GPCP) during 1979-2005 (Adler et al. 2003).

\section{Mean state and interannual variability}

Figure 1 shows the climatology of JJA-mean (June, July and August) SST during the period 1960-1978, 1979-1993 and 1994-2005. It is found that significant warming of the tropical ocean has been taking place in recent decades. In observations, compared to the period1960-1978, warmer SST is found over the Indian Ocean and tropical central and eastern Pacific during 1979-1993. Maximum of the averaged SST differences between these two periods are higher than $0.5^{\circ} \mathrm{C}$ over the ENSO regions. This SST warming pattern for the period 1979-1993 relative to the early period 1960-1978 is due to the climate shift around 1976/1977 (e.g.,Trenberth and Hurrell 
1994; Deser et al. 2004). Relatively, the warming pattern after the early 1990s exhibits significant difference to previous period. It is observed mainly over the Indo-Pacific warm pool and indicates a notable enlargement on its size. A recent study by Dong et al. (2014) suggested that internal variability, greenhouse gases and aerosols are driving factors for the decadal fluctuation of SSTs over the Pacific domain. The warming pattern after the early 1990s relative to the early period might be the combination of all these forcing factors. The above interdecadal changes are well reproduced by the models, suggesting the models shows similar bias on the mean state during these three periods.

For the SST interannual variability, significant interdecadal changes are also found after the late 1970s and early 1990s (Fig. 2). ENSO, which has been extensively reported for its influence on the WNP and East Asian summer climate (e.g., Wang et al. 2000; Li et al. 2007; Ding et al. 2014, 2015), is associated with larger standard deviation over the tropical central and eastern Pacific. During 1979-1993, significant increase on the variability is found over the tropical eastern Pacific and Indian Ocean, suggesting stronger air-sea interactions over these two regions than the previous period, as described in Huang et al. (2010) and Wang et al. (2008). The increase of tropical Indian Ocean SST variability in observations would strengthen its influence on the WNP climate. After the early 1990s, on the other hand, SST anomalies around the Maritime Continent and central Pacific show stronger interannual variability than the previous period. Increase of SST interannual variability in the equatorial Pacific, which shows an interdecadal change during the 
192

193

194

1990s, has been previously documented (e.g., Latif et al. 1997; Keenlyside et. al. 2007; Yu et al. 2010; Lee and McPhaden 2010), but not for the SST variability around the Maritime Continent. This change around the early 1990s is different to the interdecadal change around the late 1970s, with a weak decrease of the interannual variability over most of the Indian Ocean. Understanding the causes of enhanced SST interannual variability around the Maritime Continent around the early 1990s is an important research area and it needs further investigation. Additionally, for the model results, the stronger variability over the ENSO region after the late 1970s and around the Maritime Continent after the early 1990s is well simulated by the models. The large interannual variability over the Indian Ocean after the late 1970s and over the central Pacific after the early 1990s is also reproduced by the models. But the models overestimate the variability over the Indian Ocean during 1960-1978 and over the central and western Pacific during 1979-1993. This gives rise to the discrepancy over these two regions between models and observations in Figs. $2 \mathrm{~d}$ and $2 \mathrm{f}$.

Associated with the interdecadal changes of SST and interannual SST variability, significant increases of the interannual variability for the 850 -hPa zonal wind are also found around the late 1970s and early 1990s (Fig. 3). After the late 1970s, prominent increases are found around the WNP, especially for the subtropical WNP, where the interannual variability of the $850-\mathrm{hPa}$ zonal wind is more than $2.2 \mathrm{~m} \mathrm{~s}^{-1}$. On the other hand, the variability enhances significantly over the tropical WNP after the early 1990s. The intensity is larger than $3 \mathrm{~m} \mathrm{~s}^{-1}$ around the Philippine Sea. Additionally, the models simulate well the variability during 1979-1993 and 1994-2005, but show 
214 larger variability around the WNP during 1960-1978 than observations. In general,

215 the above significant interdecadal changes on the mean state and interannual

216 variability around the late 1970s and early 1990s provide backgrounds to the changes

217 of air-sea interactions related to the WNP summer climate and seasonal predictions.

\section{4. Interdecadal changes of the WNP summer prediction}

The WNP summer monsoon index (WNPMI), which is defined as the difference of the JJA-mean $850-\mathrm{hPa}$ zonal wind anomalies between $\left(5^{\circ}-15^{\circ} \mathrm{N}, 100^{\circ}-130^{\circ} \mathrm{E}\right)$ and $\left(20^{\circ}-30^{\circ} \mathrm{N}, 110^{\circ}-140^{\circ} \mathrm{E}\right)$, is used to measure the intensity of the interannual variation of the WNP lower-tropospheric circulation following Wang and Fan (1999). A positive (negative) index means an anomalous cyclonic (anticyclonic) circulation. The anomalous cyclone/anticyclone over the WNP, which is well described by the WNPMI, is the dominant mode of the lower-tropospheric wind anomalies over the WNP and plays a key role in the relationship between ENSO and the WNP/East Asian the WNPMI during the hindcast period (Li et al. 2012). ENSEMBLES show considerable capability in capturing the interannual variation of predictions and the 9-year running correlation of them. It is found that the predictability of the WNPMI exhibits an interdecadal change with higher predictability since the late 1970s, particularly after the early 1990s. The prediction skill is relatively low before the late 1970s. The models demonstrate certain inability

235 in capturing the WNPMI in most years during this period, especially from the late 
1960s to late 1970 s with the running correlation not exceeding the $95 \%$ confidence level. The correlation coefficient between the observed and MME-predicted WNPMI is only 0.4 during 1960-1978 (Table 1), in spite of that the WNPMI is well predicted in the early 1960s. After the late 1970s, the prediction skill increases evidently. The 9-yr running correlations are at the $95 \%$ confidence level during almost all the years. The corresponding correlation coefficient is 0.67 during 1979-1993 (Table 1).

Furthermore, more significant increase of the WNPMI prediction skill is found after the early 1990s. The running correlation coefficients remain to be higher than 0.8 and the MME predictions well reproduce the observed WNPMI in all the years except the negative anomaly in 1996. The bad prediction in 1996 might be caused by the frequent tropical cyclones, which are difficult for the models in describing them (Chan 2005; Li et al. 2014). The stable and high prediction skill after 1993/1994 acts as one of the most important reasons for selecting it as the separating point. Additionally, this separating point consists well with many previous works (e.g., Kwon et al. 2005; Lee et al. 2014; He and Zhou 2015), in which significant interdecadal changes of monsoon system are found around the early 1990s. The above considerable reinforcement of the predictability is also reflected by the different skill before and after 1993/94 (Table 1). The correlation coefficient between the observed and MME-predicted WNPMI reaches up to 0.9 during 1994-2005. The above decadal changes can be evidently detected from all the five models (Table 1). The correlations shown by the five models correspond well to the MME prediction, in which most of them exceed the 95\% confidence level during 1979-1993, and become much larger 
after 1994. The ECMWF, which shows the highest prediction correlation among the models during 1979-1993, displays relatively weak increase of the prediction skill after 1994. The consistency between the models confirms that the prediction skill of the WNP summer monsoon exhibits significant interdecadal changes around the late 1970s and early 1990s.

Pronounced interdecadal changes of the WNPMI interannual variability are also found with higher standard deviation (SD) since the late 1970s and after the early 1990s(Table 2), corresponding to the decadal changes of the prediction skill. The observed SD increases from $1.39 \mathrm{~m} \mathrm{~s}^{-1}$ in $1960-1978$ to $2.45 \mathrm{~m} \mathrm{~s}^{-1}$ in $1979-2005$. It arises mainly from the subtropical WNP as shown in Fig. 3c. After the early 1990s, interannual variability of the observed WNPMI also strengthens significantly, corresponding well to that shown in Fig. 3e. Actually, the variability of the WNPMI is to some extent positively correlated with the predictability of the summer anomalies over the WNP and East Asian sector (Sun and Wang 2013). The larger interannual variability after the late 1970s and early 1990s might help better prediction of the WNPMI. In addition, the models reproduce the strengthened interannual variability after the late 1970s and early 1990s, but overestimate its intensity before 1979.

Figure 5 shows the temporal correlation coefficient (TCC) of the $850-\mathrm{hPa}$ zonal wind and SST anomalies during 1960-1978 and 1979-1993. Before the late 1970s, high skills of the lower-tropospheric zonal wind are mainly confined to the warm pool regions (Fig. 5a). This connects to the good prediction of the SST anomalies over the tropical Pacific (Fig. 5d). But the skills of the SSTs over the tropical Indian Ocean are 
low with the coefficient over most of the regions not exceeding the $95 \%$ confidence level, especially over its eastern part. Low skills are also found over the subtropical WNP, both for the SST and wind anomalies, suggesting the model's deficiency in well describing local air-sea interaction over the subtropical WNP during 1960-1978. This corresponds well to the low prediction correlation of the WNPMI shown in Fig. 4. After the late 1970s, significant improvements on the WNP summer prediction are shown by the models, especially over the subtropical WNP (Figs. 5b and 5d). The regions with the TCC of lower-tropospheric zonal winds exceeding the 95\% confidence level extend north to $40^{\circ} \mathrm{N}$, which is associated with local high SST skills. Improvement of the prediction skill after the late 1970s is also found over the tropical Indian Ocean, where the TCC skills for SST anomalies over most of this region are larger than 0.7. The above improvements on the summer prediction after the late 1970s are better described by the differences of TCC between these two periods (Figs. 5c and 5f). To be mentioned, the most profound increase of the SST prediction skill over the tropical Indian Ocean after the late 1970s are mainly found in its eastern part. This increase, associating with those of the subtropical WNP anomalies, may suggest a physical consistency between this SST and lower-tropospheric wind anomalies over these regions. Meanwhile, good predictions on the WNP anticyclone/cyclone and the SST anomalies over the tropical Indian Ocean are related to the improvement on the prediction skills of lower-tropospheric zonal wind from the Maritime Continent to the tropical Indian Ocean, which act as a linkage between the tropical Indian Ocean and the WNP (e.g., Yang et al. 2007; Li et al. 2008; Xie et al. 2009). 

different characteristics relative to that around the late 1970s, as shown in Fig. 6. During 1994-2005, the models show better capability in predicting the anomalies mainly around the WNP and Maritime Continent. Compared with those during 1979-1993 (Figs. 5b and 5e), the high skills of the lower-tropospheric zonal winds extend more westward and cover most regions of the South China Sea, Indo-China

Peninsula and Bay of Bengal (Fig. 6a). This is associated with the good prediction of precipitation around the Maritime Continent, east of the Philippines and the tropical eastern Indian Ocean (Fig. 6d), where the prediction skills are relatively low for the previous period (Fig. 5b). These improvements correspond well to the good prediction of the WNPMI after the early 1990s (Fig. 4). Relatively, the SST anomalies over most tropical Indian Ocean are not well predicted after the early 1990s with the TCCs not exceeding the $95 \%$ confidence level over most regions (Fig. 6c), suggesting an independence of the improvement on the WNP prediction to the remote forcing of tropical Indian Ocean SST. The prediction correlations of SST anomalies are high around the Maritime Continent and east edge of the tropical Indian Ocean. The above decadal changes around the early 1990s are further confirmed by the differences of TCC between 1994-2005 and 1979-1993 (Figs. 6b, 6d and 6f), indicating that a different but particular prediction pattern appears after the early 1990s. These TCC differences indicate a better prediction over the South China Sea, Indo-China Peninsula and Bay of Bengal for the $850-\mathrm{hPa}$ zonal winds after the early 1990s, associating with significant improvements for the SSTs over the Maritime Continent 
and precipitation anomalies around the Philippines and tropical eastern Indian ocean, but with lower prediction skills for the SSTs over the tropical western Indian Ocean.

\section{Possible reasons related to the interdecadal changes}

\subsection{Around the late 1970s}

In observations, the summer anomalies related to the interannual variation of the WNPMI show significant interdecadal change around the late 1970s and are illustrated in Fig. 7. During 1960-1978, associated with a positive WNPMI is a remarkable wave-like pattern of the lower-tropospheric circulation, with an anomalous cyclonic circulation along $20^{\circ} \mathrm{N}$ of the WNP and an anomalous anticyclonic circulation along $40^{\circ} \mathrm{N}$ of North Pacific (Fig. 7a). These anomalies are not just confined over the WNP but also extend eastward and occupy almost the whole North Pacific. The corresponding SST anomalies exhibit a significant belt seesaw pattern in the meridional direction over North Pacific (Fig. 7c), which is well consistent with the lower-tropospheric circulation. The cyclonic (anticyclonic) circulation anomaly along $20^{\circ} \mathrm{N}\left(40^{\circ} \mathrm{N}\right)$ induces upwelling (downwelling) and favors the negative (positive) SST anomalies. In the tropics, there are negative SST anomalies in the eastern Indian Ocean and the South China Sea, and positive anomalies in the eastern Pacific. However, these SST anomalies are weak and essentially insignificant. During 1979-1993, a significant wave-like pattern of the lower-tropospheric circulation in the meridional direction is also found over the WNP, but shows different features (Fig. 7b). The anomalies locate mainly over the WNP, 
not extending eastward over North Pacific as the previous period. Furthermore, the cyclonic circulation over the WNP is associated with a stronger intensity, corresponding to the enhancement of the interannual variability of the WNPMI after the late 1970s (Table 2). Related to a positive WNPMI, negative SST anomalies are found over the tropical Indian Ocean and with significant anomalies around the north Indian Ocean and around the Philippines (Fig. 7d), suggesting a Pacific-Japan and Indian Ocean coupled mode as in Kosaka et al. (2013).

In the ENSEMBLES MME prediction, the Pacific-Japan and Indian Ocean coupled mode is well reproduced in both the periods (Fig. 8). The cyclonic anomaly over the WNP is closely related to the westerly anomaly over the northern Indian Ocean (Figs. 8a and 8b). This coupled mode is associated with the significant negative SST anomalies in the eastern Indian Ocean and the South China Sea (Figs. $8 \mathrm{c}$ and $8 \mathrm{~d}$ ), and associated with the positive precipitation anomaly in the Philippine Sea and negative anomaly in the eastern Indian Ocean and the Maritime Continent (Figs. 8e and 8f).

However, there are some discrepancies between prediction and observations. The extra-tropical anomalies associated with the WNPMI in observations are not reproduced in the prediction. In addition, the models tend to overestimate the negative SST and precipitation anomalies in the eastern Indian Ocean during 1960-1978 in comparison with the period 1979-1993.

The Pacific-Japan and Indian Ocean coupled mode in the ENSEMBLES MME prediction is significantly related to the SST anomalies in the eastern Indian Ocean. 
This result is in agreement with many previous studies (e.g., Xie et al. 2009; Huang et al. 2010; Li et al. 2012). In these studies, the WNPMI-related SST anomalies appear in the entire tropical Indian Ocean. Xie et al. (2009) used an atmospheric general circulation model (AGCM) to investigate the contributions of north and south Indian Ocean to the WNP climate variability, and suggested the north Indian Ocean plays an important role in the teleconnections between the tropical Indian Ocean and WNP. However, the present results of prediction suggest that the SST anomalies in the eastern Indian Ocean, rather than the north Indian Ocean, play a dominant role. Actually, the local SST-Precipitation relationship is significantly positive over the tropical eastern Indian Ocean, but weak or even negative over the other regions of tropical Indian Ocean (e.g., Ding et al. 2014; Kumar et al. 2013; Lu and Lu 2014). Therefore, the ocean variability drives the atmosphere in the tropical eastern Indian Ocean, and provides more prediction signals to the models.

The eastern Indian Ocean-WNP coupled mode exists during the both periods in the predictions. Therefore, the reproducibility of this mode cannot be used to interpret the difference in predictability of WNPMI between these two periods. The reason for the difference in predictability may lie in the difference of predictability of eastern Indian Ocean SSTs. This hypothesis can be supported by the increase of SST TCC in the eastern Indian Ocean (Fig. 5f). The TCC of SST anomalies averaged over the eastern Indian Ocean $\left(20^{\circ} \mathrm{S}-20^{\circ} \mathrm{N}, 80^{\circ}-100^{\circ} \mathrm{E}\right)$ is 0.37 during $1960-1978$, and increases to 0.84 during 1979-1993. Therefore, it can be concluded that the models capture the eastern Indian Ocean-WNP coupled mode during both the periods, and 
higher predictability of the eastern Indian Ocean during the later period leads to higher predictability of the WNPMI.

\subsection{Around the early $1990 \mathrm{~s}$}

Figure 9 shows the summer anomalies related to the interannual variation of the WNPMI after the early 1990s. In observations, a remarkable wave-like pattern of the lower-tropospheric circulation is also found over the WNP, but the related air-sea interactions are quite different to the previous period. A dipole SST pattern, with significant negative anomalies around the Maritime Continent and positive anomalies over the equatorial central Pacific, is associated with a positive WNPMI. The correlation coefficient between the WNPMI and the dipole SST pattern, which is defined as the SST differences between $\left(10^{\circ} \mathrm{S}-10^{\circ} \mathrm{N}, 100^{\circ}-150^{\circ} \mathrm{E}\right)$ and $\left(5^{\circ} \mathrm{S}-5^{\circ} \mathrm{N}\right.$, $170^{\circ} \mathrm{E}-130^{\circ} \mathrm{W}$ ) (according to Fig. 9c), is 0.70 in observations. This east-west dipole SST pattern with cold SST over the Maritime Continent and warm SST over the central equatorial Pacific Ocean favors strong westerly anomalies via atmospheric heating, induces convergence by the Ekman friction, further enhances the convection around the Philippine Sea and thus contributes to the WNP lower-tropospheric cyclonic anomaly (Fig.9) (Lu 2001; Terao and Kubota 2005; Xie et al. 2009; He and Zhou 2015). This pattern is coupled with a stronger precipitation anomaly around the Philippine Sea, Maritime Continent and equatorial western Pacific.

This east-west dipole SST pattern over the Maritime Continent and the central equatorial Pacific Ocean are reproduced quite well by the models (Fig. 9d). The 
correlation coefficient between this dipole SST pattern and WNPMI is 0.70 in the MME prediction, quite close to that in observations. The positive precipitation anomalies in the Philippine Sea are also well captured by the models (Fig. 9f). Higher predictability of the WNP summer climate is brought by this pattern after the early 1990s. The SST anomalies related to the WNPMI in the model predictions are apt to display a dipole pattern over the tropical regions, in all periods, as shown in Figs. 8c, $8 \mathrm{~d}$ and $9 \mathrm{~d}$. The dipole SST anomalies are not clearly appeared in observations during the first two periods before the early 1990s, but quite similar to observations during 1994-2005. These changes on the dipole SST anomalies in observations after the early 1990s correspond well to those for the SST interannual variability (Fig. 2e).

The ensemble-mean predictions are apt to display strong variability over the regions where the local SST-Precipitation relationship is positive, including the tropical eastern Indian Ocean, the Maritime Continent and the central Pacific Ocean (e.g., Ding et al. 2014; Kumar et al. 2013; Lu and Lu 2014) and providing more prediction reliability to the models. The dipole SST pattern over the Maritime Continent and central equatorial Pacific dominates the variation of the WNP summer climate after the early 1990s, both in observations and the model predictions (Fig. 9), acting as the primary sources for the predictability. This dipole SST forcing becomes stronger after the early 1990s in observations, reflecting by a higher correlation coefficient between the WNPMI and dipole SST in observations ( -0.70 after the early 1990s, -0.12 before that time). The tropical eastern Indian Ocean SST anomalies are also shown related to the WNPMI after the early 1990s, but are relatively weaker in 
observations (Figs. 9c and 9d). In general, the dipole SST pattern provides more prediction reliability to the WNP summer climate and dominates the WNP summer predictability after the early 1990s.

\section{Summary and discussion}

It has been found that pronounced interdecadal changes for the summer SST and associated interannual variability take place around the late 1970s and early 1990s. Significant warming and stronger variability over the tropical Indian Ocean and eastern Pacific are shown after the late 1970s. But the pattern is changed after the early 1990s, with the warming SST and stronger variability over the Maritime Continent and western Pacific. These changes are associated with the interdecadal changes on the predictability of the WNP summer climate, and have been well examined in this study. The ENESMBLES May-start seasonal predictions during a 46-year period from 1960 to 2005, which comprises five state-of-the-art atmosphere-ocean coupled models, are used here. The primary measurement for the prediction skill is the temporal correlation coefficient between observations and models' hindcast.

Our analyses reveal that seasonal prediction for the WNP summer anomalies exhibits a significant interdecadal shift with higher prediction skills since the late 1970s, particularly after the early 1990s. The prediction correlation of the WNPMI increases from 0.40 during 1960-1978 to 0.67 during1979-1993, displaying a projected enhancement on the predictability of the WNP climate after the late 1970s. This enhancement is associated with significant improvements of the prediction skill 
over the subtropical WNP and tropical Indian Ocean, both for the lower-tropospheric wind and SST anomalies. The prediction correlation of the WNPMI becomes further higher and reaches to 0.90 after the early 1990s (1994-2005). It is different to the changes around the late 1970s, with higher prediction skills around the South China Sea and the Philippines for the lower-tropospheric zonal wind and precipitation anomalies, and around the Maritime Continent for the SST anomalies. In addition, the interannual variability of the WNPMI increases significantly after the late 1970s, particularly after the early 1990s.

Higher predictability of tropical eastern Indian Ocean after the late 1970s gives rise to the improvement on prediction skill of the WNP anomalies. The corresponding TCC skill for the tropical eastern Indian Ocean SST increases to 0.84 during 1979-1993, which is only 0.37 during 1960-1978. A close relationship between the tropical eastern Indian Ocean SST and the WNP summer anomalies is found in the model predictions during both the periods. It corresponds well to that in observations, especially during 1979-1993. These SST anomalies are relatively weak and essentially insignificant during the previous period.

The predictable pattern related to the WNP climate is also changed around the early 1990s. During 1994-2005, the WNP anomalies are coupled with an east-west dipole SST pattern between the Maritime Continent and equatorial central Pacific in observations. It favors the convection around the Philippine Sea and the WNP lower-tropospheric circulation via atmospheric adjustment. For the model predictions, the SST anomalies related to the WNP summer climate tend to display a dipole SST 
pattern over the tropical region, with warm SSTs over the central Pacific Ocean and cold SSTs around the Maritime Continent and tropical eastern Indian Ocean (Figs. 8c, 8d and 9d). Thus, the teleconnections between the tropical dipole SST pattern and WNP summer climate work in both the model predictions and observations during 1994-2005. It would give rise to the higher predictability for the WNP summer climate after the early 1990s.

This work suggests that SST forcing from the tropical eastern Indian Ocean plays an important role in the WNP summer prediction. The corresponding physical mechanisms are not discussed in this study. In view of the positive SST-Precipitation relationship over there, it would be possible to be revealed by an AGCM SST experiment and will be investigated in our future study.

Furthermore, the present results interpret predictability and the corresponding sources for the WNP summer climate in the case of non-stationary teleconnections during recent decades. It implies a sensitivity of the prediction skills for the WNP summer anomalies to different coupled modes over the tropics. High prediction skills with more predictable signals are found in recent two decades over the WNP, presenting a basis in further investigation on seasonal prediction for the East Asian summer rainfall. Rainfall over the central China, for instance, is better captured by the models after the early 1990s (Fig. 6e). Nevertheless, this improvement seems modest, especially over the other regions of East Asia (Fig. 6f). Skillful prediction on year-to-year fluctuations of the East Asian summer rainfall remains a challenge. 
499 We thank the two anonymous reviewers for their comments and constructive 500 suggestions. This work was supported by the National Natural Science Foundation of 501 China (Grant Nos. 41305067 and 41320104007). BD is supported by the UK National 502 Centre for Atmospheric Science, funded by the Natural Environment Research 503 Council. 


\section{References}

Adler RF, Huffman GJ, Chang A, Ferraro R, et al. (2003) The Version-2 Global Precipitation Climatology Project (GPCP) monthly precipitation analysis (1979-Present). J Hydro 4:1147-1167

Chan JCL (2005) Interannual and interdecadal variations of tropical cyclone activity over the western North Pacific. Meteorology and Atmospheric Physics 89:143-152.doi:10.1007/s00703-005-0126-y

Chowdary JS, Xie S-P, Luo J-J, Hafner J, Behera S, Masumoto Y, Yamagata T (2009) Predictability of Northwest Pacific climate during summer and the role of the tropical Indian Ocean. Clim Dyn 36:607-621.doi:10.1007/s00382-009-0686-5

Deser C, Phillips AS, Hurrell JW (2004) Pacific interdecadal climate variability: Linkages between the tropics and the North Pacific during boreal winter since 1900. J Clim 17:3109-3124

Ding H, Greatbatch R, Lu J, Cash B (2015) The East Asian Summer Monsoon in pacemaker experiments driven by ENSO. Ocean Dynamics 65:385-393.doi:10.1007/s10236-014-0795-5

Ding H, Greatbatch R, Park W, Latif M, Semenov V, Sun X (2014) The variability of the East Asian summer monsoon and its relationship to ENSO in a partially coupled climate model. Clim Dyn 42:367-379.doi:10.1007/s00382-012-1642-3

Doblas-Reyes FJ, Weisheimer A, Palmer TN, Murphy JM, Smith D (2010) Forecast quality assessment of the ENSEMBLES seasonal-to-decadal Stream 2 hindcasts. ECMWF Technical Memorandum:No. 621, ECMWF, Reading, UK, 45pp 
Dong L, Zhou T, Chen X (2014) Changes of Pacific decadal variability in the twentieth century driven by internal variability, greenhouse gases, and aerosols. Geophys Res Lett 41:8570-8577.doi:10.1002/2014GL062269

He C, Zhou T (2015) Decadal change of the connection between summer western North Pacific Subtropical High and tropical SST in the early 1990s. Atmospheric Science Letters.doi:10.1002/as12.550

Huang G, Hu K, Xie S-P (2010) Strengthening of tropical Indian Ocean teleconnection to the Northwest Pacific since the mid-1970s: An atmospheric GCM study. J Clim 23:5294-5304

Huang R, Sun F (1992) Impacts of the tropical western Pacific on the East Asian summer monsoon. J Meteorol Soc Japan 70:243-256

Huang Y, Wang H, Fan K, Gao Y (2015) The western Pacific subtropical high after the 1970s: westward or eastward shift? Clim Dyn 44:2035-2047.doi:10.1007/s00382-014-2194-5

Kalnay E, Kanamitsu M, Kistler R, Collins W, Deaven D, Gandin L, Iredell M, Saha S, White G, Woollen J (1996) The NCEP/NCAR 40-Year reanalysis project. Bull Am Meteorol Soc 77:437-471

Keenlyside NS, Latif M, Dürkop A (2007) On Sub-ENSO Variability. J Clim 20:3452-3469.doi:10.1175/JCLI4199.1

Kosaka Y, Xie S-P, Lau N-C, Vecchi GA (2013) Origin of seasonal predictability for summer climate over the Northwestern Pacific. Proceedings of the National Academy of Sciences 110:7574-7579 
Kumar A, Chen M, Wang W (2013) Understanding prediction skill of seasonal mean $\begin{array}{lllll}\text { precipitation } & \text { over the } & \text { tropics. }\end{array}$ 26:5674-5681.doi:10.1175/JCLI-D-12-00731.1

Kwon M, Jhun J-G, Wang B, An S-I, Kug J-S (2005) Decadal change in relationship between east Asian and WNP summer monsoons. Geophys Res Lett 32:L16709.doi:10.1029/2005gl023026

Latif M, Kleeman R, Eckert C (1997) Greenhouse warming, decadal variability, or El Niño? An attempt to understand the anomalous 1990s. J Clim 10:2221-2239

Lee E-J, Ha K-J, Jhun J-G (2014) Interdecadal changes in interannual variability of the global monsoon precipitation and interrelationships among its subcomponents. Clim Dyn 42:2585-2601.doi:10.1007/s00382-013-1762-4

Lee S-S, Lee J-Y, Ha K-J, Wang B, Schemm J (2011) Deficiencies and possibilities for long-lead coupled climate prediction of the western North Pacific-East $\begin{array}{llll}\text { Asian } & \text { summer } & \text { monsoon. }\end{array}$ 36:1173-1188.doi:10.1007/s00382-010-0832-0

Lee T, McPhaden MJ (2010) Increasing intensity of El Niño in the central-equatorial Pacific. Geophys Res Lett 37:L14603.doi:10.1029/2010GL044007

Li C, Lu R, Dong B (2012) Predictability of the western North Pacific summer climate demonstrated by the coupled models of ENSEMBLES. Clim Dyn 39:329-346.doi:10.1007/s00382-011-1274-z

Li C, Lu R, Dong B (2014) Predictability of the western North Pacific summer climate associated with different ENSO phases by ENSEMBLES multi-model 
Li S, Lu J, Huang G, Hu K (2008) Tropical Indian Ocean basin warming and East

$$
\begin{aligned}
& \text { Asian summer monsoon: A multiple AGCM study. J Clim } \\
& \text { 21:6080-6088.doi:10.1175/2008jcli2433.1 }
\end{aligned}
$$

Li Y, Lu R, Dong B (2007) The ENSO-Asian monsoon interaction in a coupled ocean-atmosphere GCM. J Clim 20:5164-5177.doi:10.1175/jcli4289.1

Lu R (2001) Atmospheric circulations and sea surface temperatures related to the convection over the western Pacific warm pool on the interannual scale. Adv Atmos Sci 18:270-282

Lu R, Dong B (2001) Westward extension of North Pacific subtropical high in summer. J Meteorol Soc Japan 79:1229-1241

$\mathrm{Lu} \mathrm{R}$, Fu Y (2009) Intensification of East Asian summer rainfall interannual variability in the twenty-first century simulated by 12 CMIP3 coupled models. J Clim 23:3316-3331.doi:10.1175/2009jcli3130.1

Lu R, Lu S (2014) Local and remote factors affecting the SST-precipitation relationship over the western North Pacific during summer. J Clim 27:5132-5147.doi:10.1175/JCLI-D-13-00510.1

Park J-Y, Jhun J-G, Yim S-Y, Kim W-M (2010) Decadal changes in two types of the western North Pacific subtropical high in boreal summer associated with Asian summer monsoon/El Niño-Southern Oscillation connections. Journal of Geophysical Research: Atmospheres 115:D21129.doi:10.1029/2009JD013642

Smith TM, Reynolds RW (2004) Improved extended reconstruction of SST 
Sui C-H, Chung P-H, Li T (2007) Interannual and interdecadal variability of the summertime western North Pacific subtropical high. Geophys Res Lett 34:L11701.doi:10.1029/2006GL029204

Sun B, Wang H (2013) Larger variability, better predictability? Int J Climatol 33:2341-2351.doi:10.1002/joc.358

Terao T, Kubota T (2005) East-west SST contrast over the tropical oceans and the post El Niño western North Pacific summer monsoon. Geophys Res Lett 32:L15706.doi:10.1029/2005GL023010

Trenberth KE, Hurrell JW (1994) Decadal atmosphere-ocean variations in the Pacific. Clim Dyn 9:303-319

van der Linden P, Mitchell FJB, (eds.) (2009) ENSEMBLES: Climate Change and its Impact: Summary of research and results from ENSEMBLES project.Met Office Hadley Centre, FitzRoy Road, Exeter EX1 3PB, UK, 160pp

Wang B, Fan Z (1999) Choice of South Asian summer monsoon indices. Bull Am Meteorol Soc 80:629-638

Wang B, Lee J-Y, Kang I-S, Shukla J, et al. (2009) Advance and prospectus of seasonal prediction: assessment of the APCC/CliPAS 14-model ensemble retrospective seasonal prediction (1980-2004). Clim Dyn 33:93-117.doi:10.1007/s00382-008-0460-0

Wang B, Wu R, Fu X (2000) Pacific-East Asian teleconnection: how does ENSO affect East Asian climate? J Clim 13:1517-1536 
615

616

617

618

619

620

621

622

623

624

625

626

627

628

629

630

631

632

633

634

635

636

Wang B, Yang J, Zhou T (2008) Interdecadal changes in the major modes of Asian-Australian onscoon variability: Strengthening relationship with ENSO since the late 1970s. J Clim 21:1771-1789

Weisheimer A, Doblas-Reyes FJ, Palmer TN, Alessandri A, Arribas A, Déqué M, Keenlyside N, MacVean M, Navarra A, Rogel P (2009) ENSEMBLES: A new multi-model ensemble for seasonal-to-annual predictions-Skill and progress beyond DEMETER in forecasting tropical Pacific SSTs. Geophys Res Lett 36:L21711.doi:10.1029/2009GL040896

Wu R, Wen Z, Yang S, Li Y (2010) An interdecadal change in southern China summer rainfall around 1992/93. J Clim 23:2389-2403

Xie S-P, Du Y, Huang G, Zheng X-T, Tokinaga H, Hu K, Liu Q (2010) Decadal Shift in El Niño Influences on Indo-Western Pacific and East Asian Climate in the 1970s. J Clim 23:3352-3368.doi:10.1175/2010JCLI3429.1

Xie S-P, Hu K, Hafner J, Tokinaga H, Du Y, Huang G, Sampe T (2009) Indian Ocean capacitor effect on Indo-Western Pacific climate during the summer following El Niño. J Clim 22:730-747

Yang J, Liu Q, Xie S-P, Liu Z, Wu L (2007) Impact of the Indian Ocean SST basin mode on the Asian summer monsoon. Geophys Res Lett 34:L02708.doi:10.1029/2006GL028571

Yim S-Y, Yeh S-W, Wu R, Jhun J-G (2008) The influence of ENSO on decadal variations in the relationship between the east Asian and western North Pacific summer monsoons. J Clim 21:3165-3179.doi:10.1175/2007jcli1948.1 
637 Yu J-Y, Kao H-Y, Lee T (2010) Subtropics-Related Interannual Sea Surface 638 Temperature Variability in the Central Equatorial Pacific. J Clim $639 \quad 23: 2869-2884 . d o i: 10.1175 / 2010 J C L I 3171.1$

640 
Table 1 Correlation coefficients of the WNPMI between the observations and models. correlation coefficients at $95 \%$ and $99 \%$ confidence level, respectively

\section{Figure Captions}

Figure 1 Climatology of JJA-mean SST for observations (left) and the ENSEMBLES MME prediction (right) during 1960-1978 (upper), 1979-1993 (middle) and 1994-2005 (lower). Unit: ${ }^{\circ} \mathrm{C}$. The shading represents differences of SST to the previous period

Figure 2 Similar to Fig. 1, but for the interannual variability of the JJA-mean SST

Figure 3 Interannual variability of $850-\mathrm{hPa}$ zonal wind for observations (left) and the ENSEMBLES MME prediction (right). Unit: $\mathrm{m} \mathrm{s}^{-1}$. The contours represent where differences of SD to previous period are larger (smaller) than $0.4(-0.4)$ $\mathrm{m} \mathrm{s}^{-1}$

Figure 4 a Time series of the normalized WNP summer monsoon index (WNPMI) for observations (solid black line), the MME predictions (dashed red line) and $\mathbf{b}$ the 9-year running correlation of the WNPMI between the observations and MME predictions. The dashed lines in $\mathbf{b}$ represent statistically significance of 
663

664

665

666

667

668

669

670

671

672

673

674

675

676

677

678

679

680

681

682

683

Figure 5 Temporal correlation coefficients (TCC) of JJA-mean 850-hPa zonal wind (upper) and SST anomalies (lower) between the observations and MME predictions during 1960-1978 (left), 1979-1993 (middle) and the differences between these two periods (right). The contours represent statistically significance of the correlation coefficients at $95 \%$ and $99 \%$ confidence levels, respectively

Figure 6 Same as Fig.5, but for the TCC of JJA-mean 850-hPa zonal wind (upper), SST (middle) and precipitation (lower) anomalies during 1994-2005 (left) and the differences (right) to that during 1979-1993

Figure 7 Regression of the 850-hPa winds (upper) and SST (lower) anomalies onto the normalized WNPMI in observations during 1960-1978 (left) and 1979-1993 (right). The shading indicates the regions where the anomalies exceed the $95 \%$ confidence level. Interval of the SST anomaly is $0.1^{\circ} \mathrm{C}$

Figure 8 Same as Fig. 7, but for the 850-hPa zonal wind (upper), SST (middle) and precipitation (lower) anomalies in the ENSEMBLES MME prediction. Interval of the precipitation anomaly is $0.4 \mathrm{~mm} \mathrm{day}^{-1}$

Figure 9 Regression of the 850-hPa zonal wind (upper), SST (middle) and precipitation (lower) anomalies onto the normalized WNPMI in observations (left) and the ENSEMBLES MME prediction (right) during 1994-2005. Intervals of the SST and precipitation anomalies are $0.1^{\circ} \mathrm{Cand} 0.4 \mathrm{~mm} \mathrm{day}^{-1}$, respectively 
Table 1 Correlation coefficients of the WNPMI between the observations and models.

The values underlined and in bold represent statistically significance of the correlation coefficients at $95 \%$ and $99 \%$ confidence level, respectively

688

\begin{tabular}{c|ccc}
\hline Corr. OBS & $1960-1978$ & $1979-1993$ & $1994-2005$ \\
\hline MME & 0.40 & $\mathbf{0 . 6 7}$ & $\mathbf{0 . 9 0}$ \\
ECMWF & 0.42 & $\mathbf{0 . 7 3}$ & $\mathbf{0 . 7 9}$ \\
IFM-GEOMAR & 0.33 & $\underline{0.62}$ & $\mathbf{0 . 9 0}$ \\
MF & 0.17 & $\underline{0.63}$ & $\mathbf{0 . 7 8}$ \\
UKMO & $\underline{0.47}$ & 0.46 & $\mathbf{0 . 8 0}$ \\
CMCC-INGV & 0.26 & $\underline{0.63}$ & $\mathbf{0 . 8 2}$ \\
\hline
\end{tabular}

689

690 
691 Table 2 Standard deviation (SD) of the observed and predicted WNPMI (Unit: $\mathrm{m} \mathrm{s}^{-1}$ ). 692 The predicted SD is calculated as the averaged SD for each ensemble members 693

\begin{tabular}{c|ccc}
\hline SD of the WNPMI & $1960-1978$ & $1979-1993$ & $1994-2005$ \\
\hline OBS & 1.39 & 2.14 & 2.87 \\
MME & 2.0 & 2.28 & 2.71 \\
ECMWF & 1.91 & 2.36 & 2.61 \\
IFM-GEOMAR & 2.15 & 2.73 & 2.91 \\
MF & 1.55 & 2.12 & 2.33 \\
UKMO & 2.18 & 2.13 & 2.80 \\
CMCC-INGV & 2.23 & 2.00 & 2.91 \\
\hline
\end{tabular}

694

695 
JJA SST
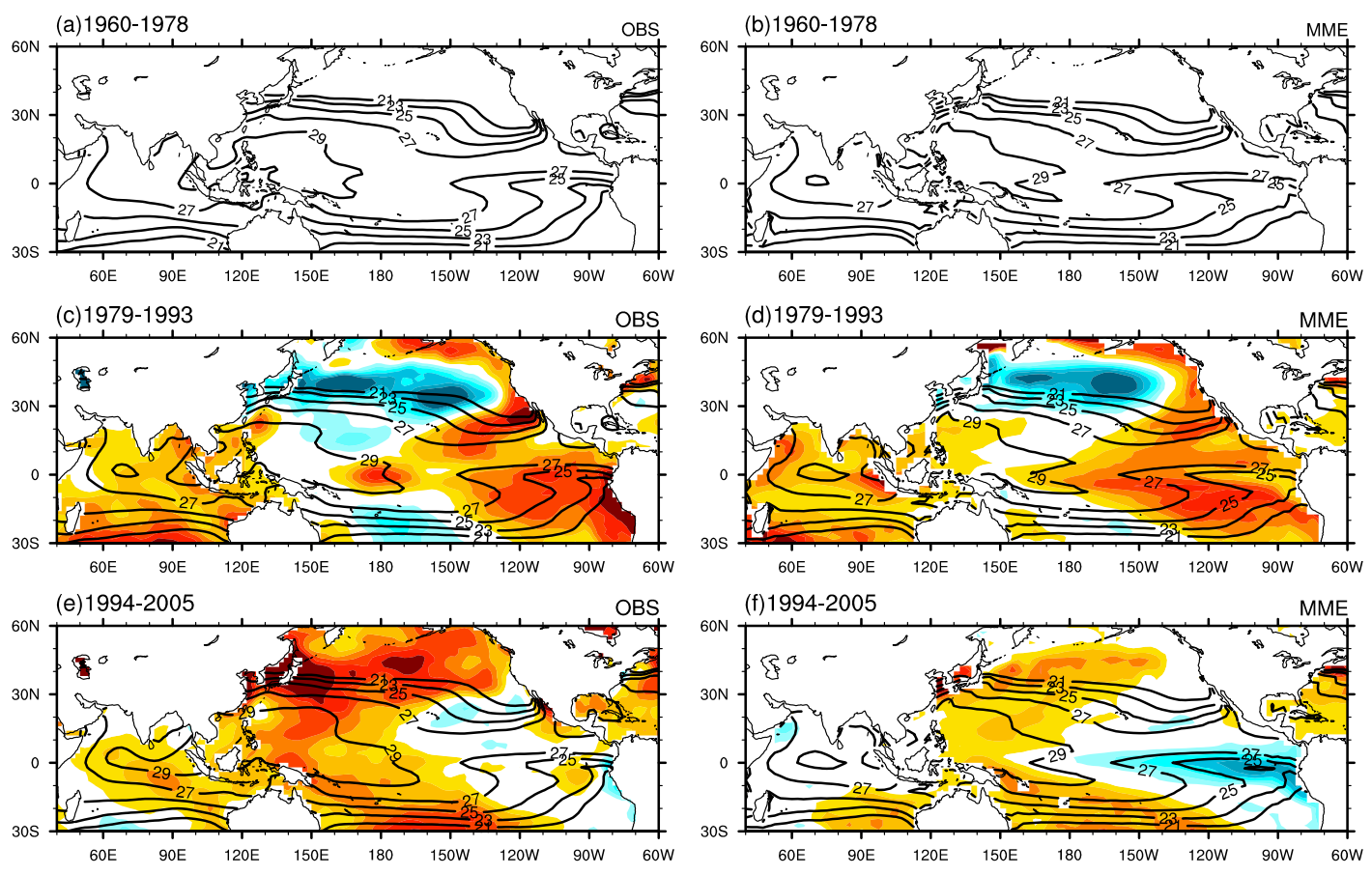

696

$\begin{array}{ccccccccccccccc}\mid & \mid & \mid & \mid & \mid & \mid & \mid & \mid & \mid & \mid & & \\ -0.6 & -0.5 & -0.4 & -0.3 & -0.2 & -0.1 & 0.1 & 0.2 & 0.3 & 0.4 & 0.5 & 0.6\end{array}$

697 Figure 1 Climatology of JJA-mean SST for observations (left) and the ENSEMBLES

MME prediction (right) during 1960-1978 (upper), 1979-1993 (middle) and previous period 


\section{SD of JJA SST}
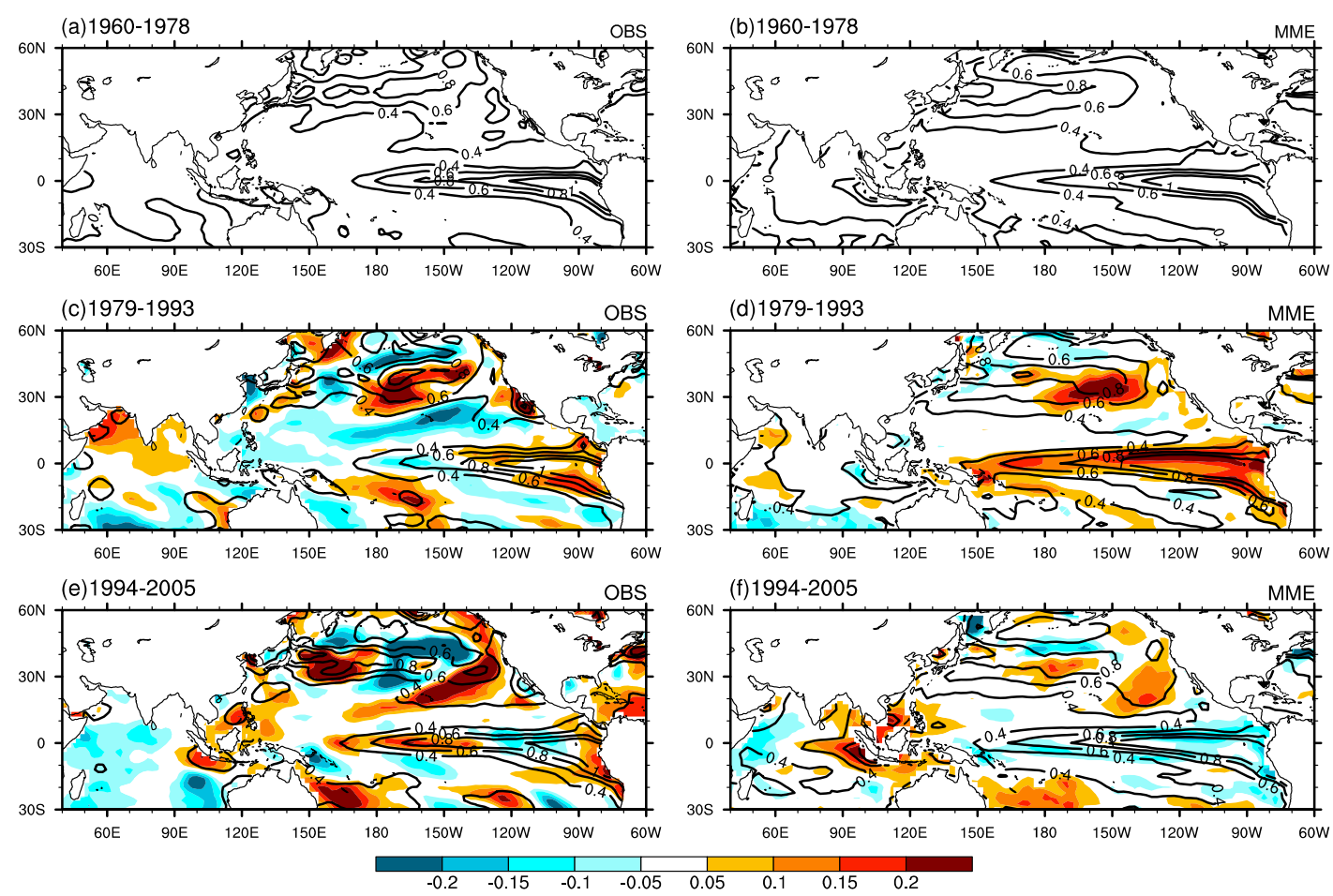

Figure 2 Similar to Fig. 1, but for the interannual variability of the JJA-mean SST 


\section{SD of JJA U850}
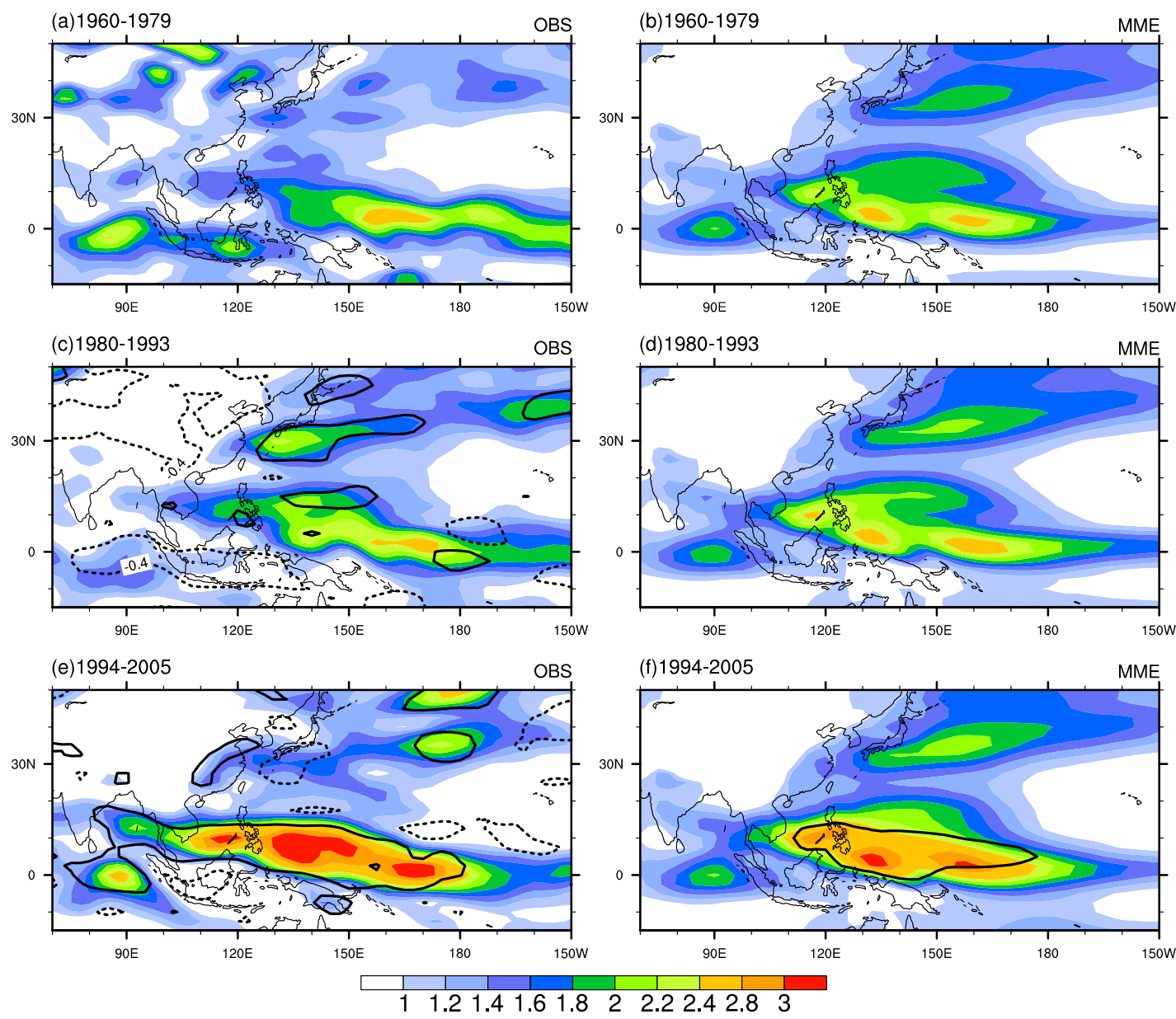

705 Figure 3 Interannual variability of 850 -hPa zonal wind for observations (left) and the

$\mathrm{m} \mathrm{s}^{-1}$ 


\section{(a)WNPMI}

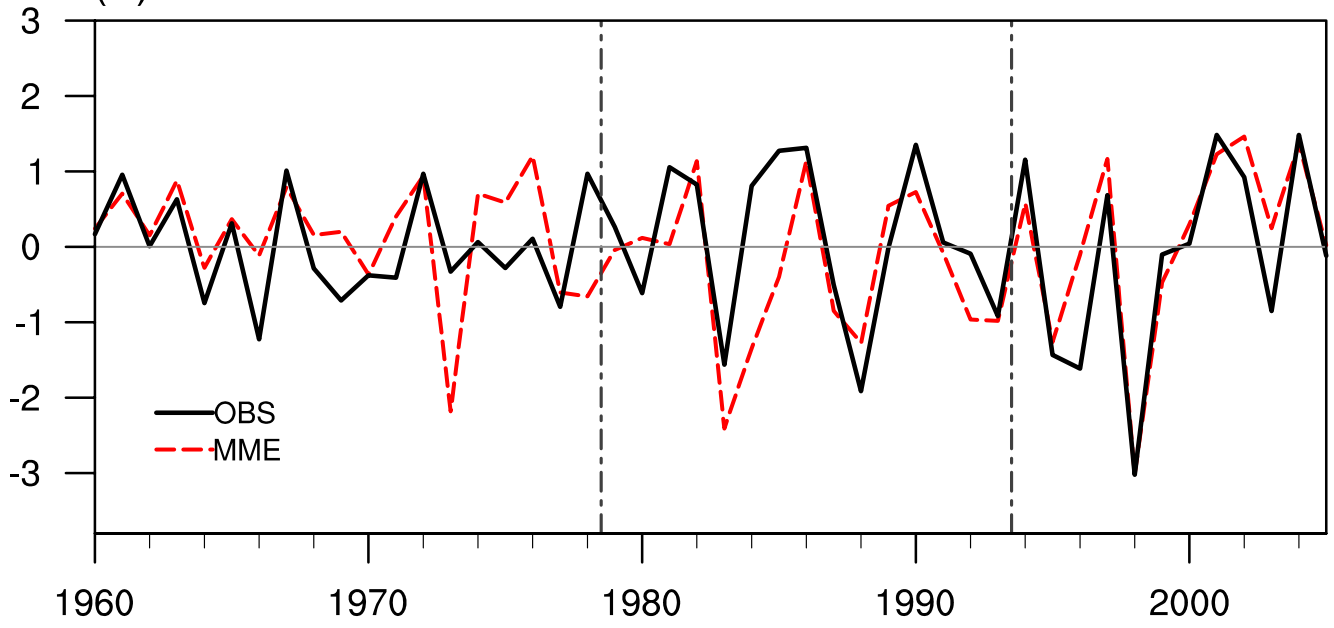

(b)9-yr Running Corr.

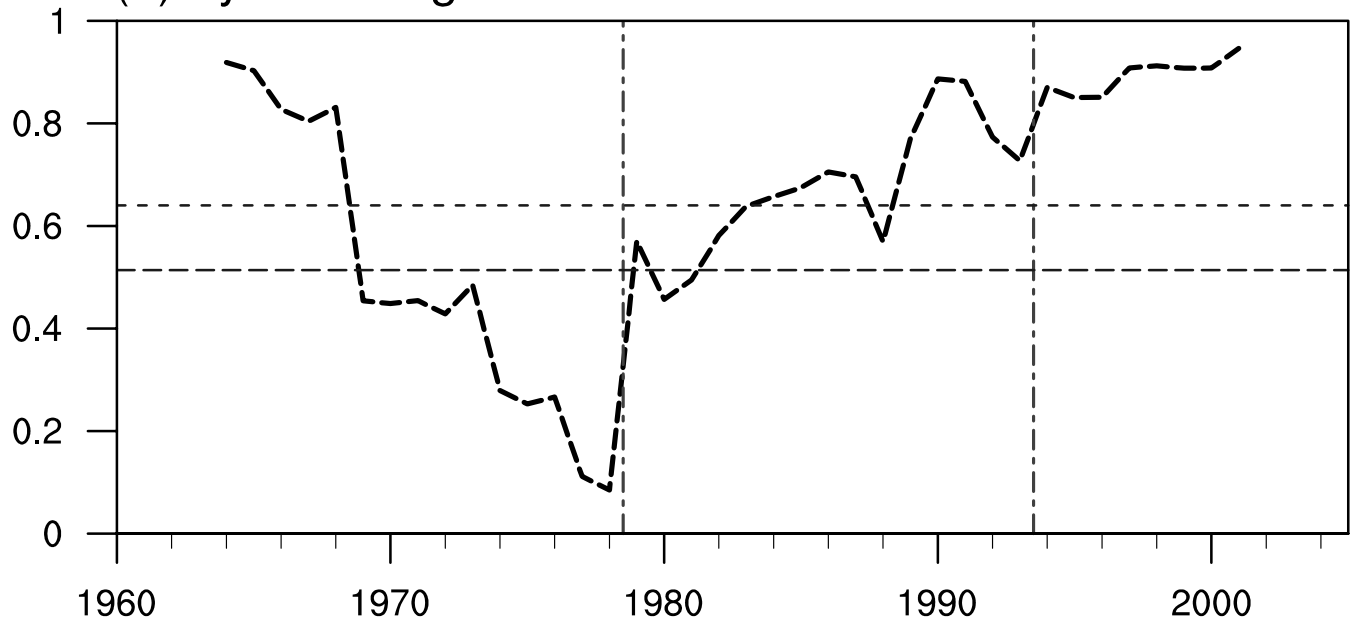

Figure 4 a Time series of the normalized WNP summer monsoon index (WNPMI) for observations (solid black line), the MME predictions (dashed red line) and b the 9-year running correlation of the WNPMI between the observations and MME predictions. The dashed lines in $\mathbf{b}$ represent statistically significance of the correlation coefficients at $95 \%$ and $99 \%$ confidence levels, respectively 

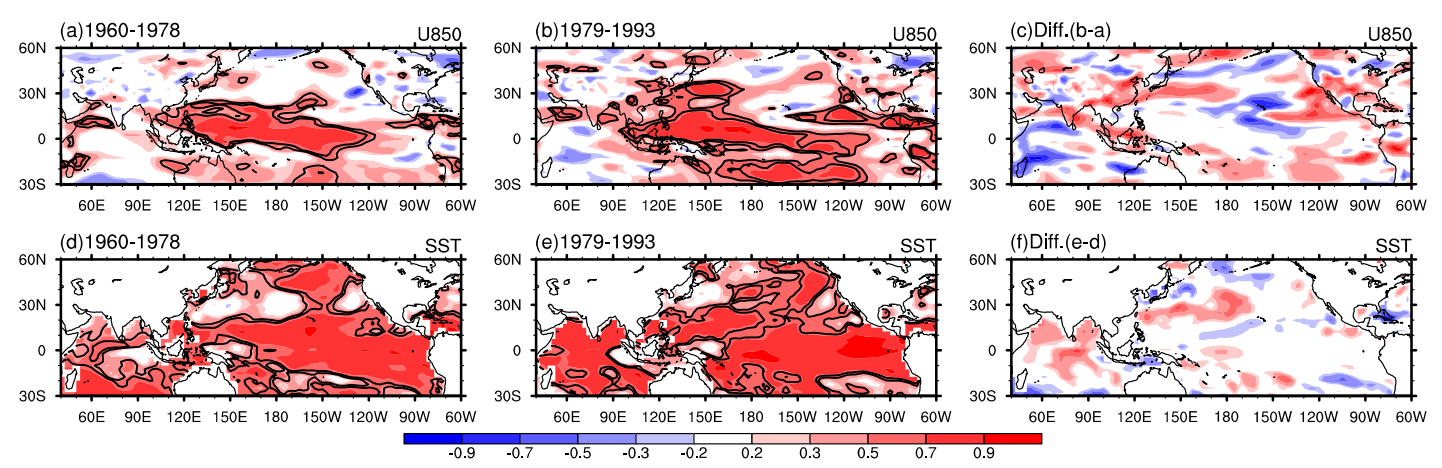

717 Figure 5 Temporal correlation coefficients (TCC) of JJA-mean 850-hPa zonal wind

718 (upper) and SST anomalies (lower) between the observations and MME 719 predictions during 1960-1978 (left), 1979-1993 (middle) and the differences 720 between these two periods (right). The contours represent statistically 721 significance of the correlation coefficients at $95 \%$ and $99 \%$ confidence levels, respectively 

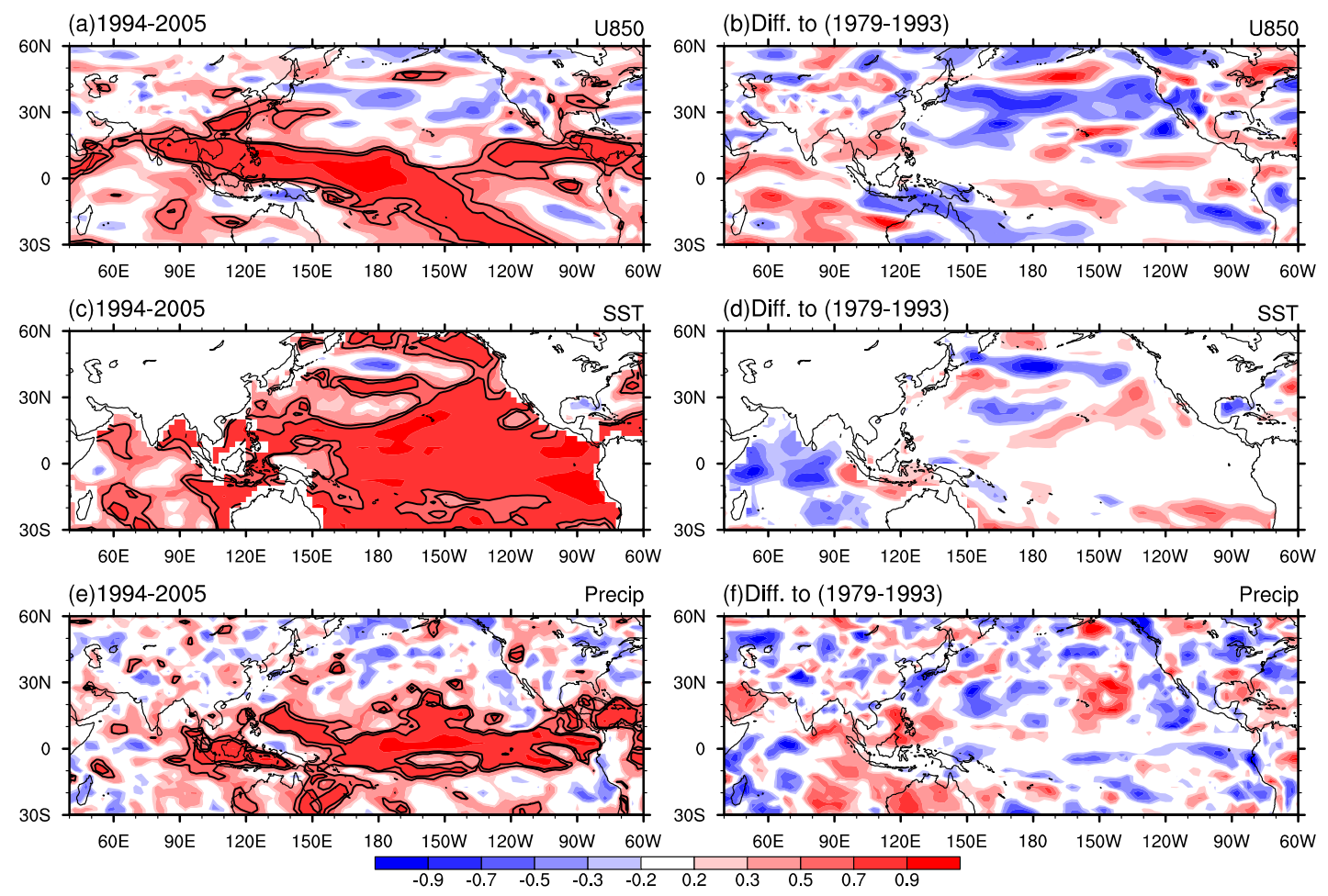

Figure 6 Same as Fig.5, but for the TCC of JJA-mean 850-hPa zonal wind (upper), SST (middle) and precipitation (lower) anomalies during 1994-2005 (left) and the differences (right) to that during 1979-1993 

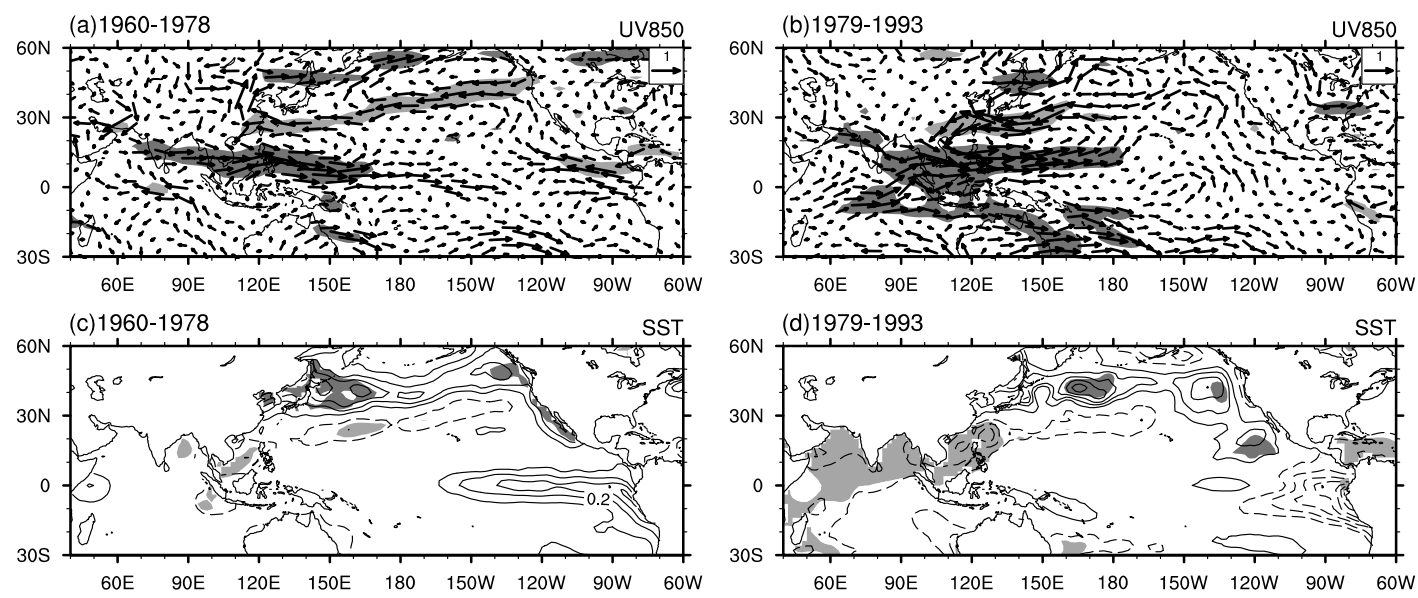

731 Figure 7 Regression of the 850-hPa winds (upper) and SST (lower) anomalies onto the normalized WNPMI in observations during 1960-1978 (left) and 1979-1993 (right). The shading indicates the regions where the anomalies exceed the $95 \%$ confidence level. Interval of the SST anomaly is $0.1^{\circ} \mathrm{C}$ 

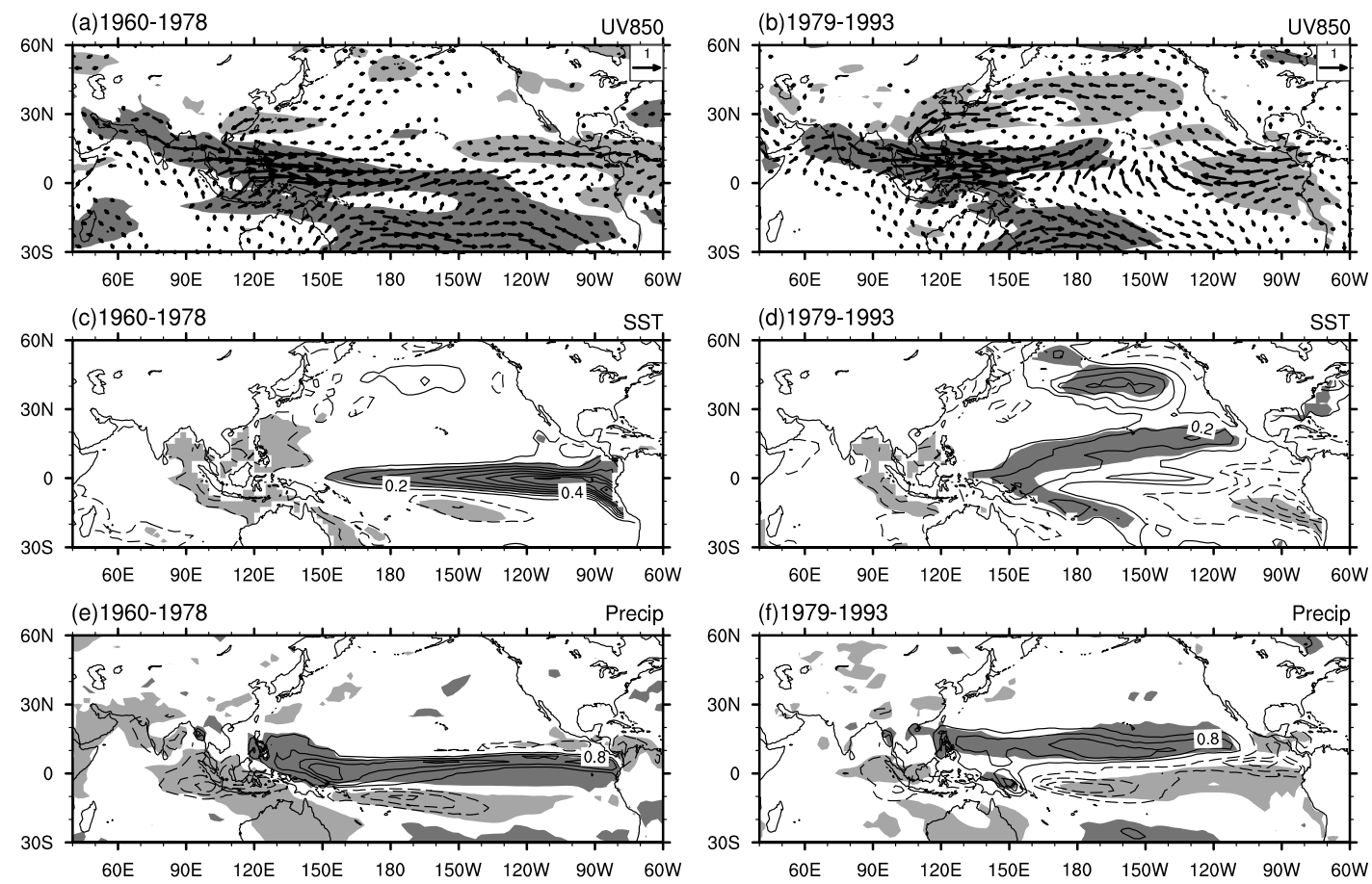

Figure 8 Same as Fig. 7, but for the 850-hPa zonal wind (upper), SST (middle) and precipitation (lower) anomalies in the ENSEMBLES MME prediction. Interval of the precipitation anomaly is $0.4 \mathrm{~mm} \mathrm{day}^{-1}$ 
Regg. onto WNPMI (1994-2005)
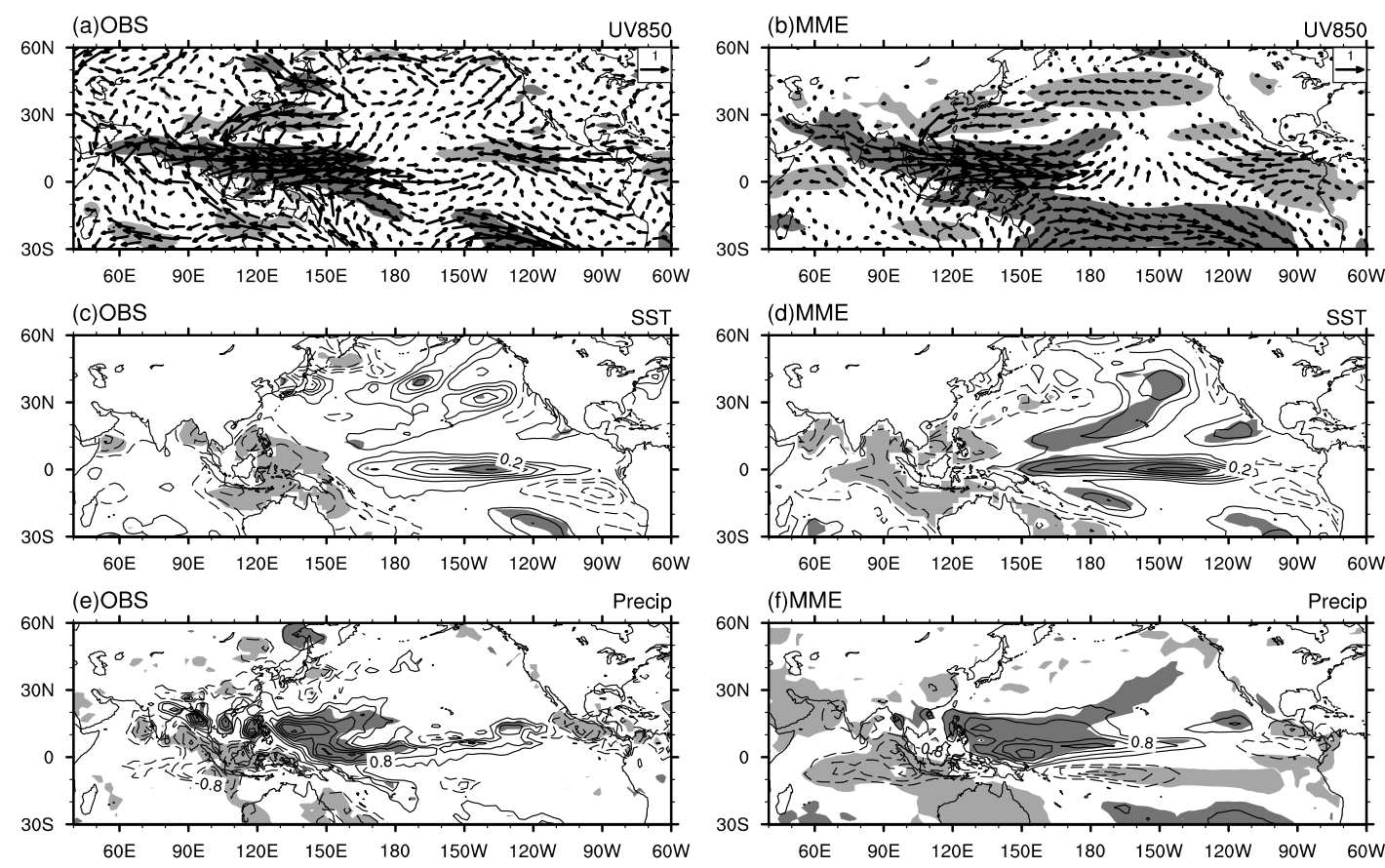

743 Figure 9 Regression of the $850-\mathrm{hPa}$ zonal wind (upper), SST (middle) and precipitation (lower) anomalies onto the normalized WNPMI in observations (left) and the ENSEMBLES MME prediction (right) during 1994-2005. Intervals of the SST and precipitation anomalies are $0.1^{\circ} \mathrm{Cand} 0.4 \mathrm{~mm}$ day $^{-1}$, respectively 